\title{
APROXIMAÇÕES AO PROBLEMA FENOMENOLÓGICO E METAFISICO DO SENTIMENTO EM RENAUD BARBARAS
}

\author{
Approaches to the phenomenological and metaphysical problem of feeling in Renaud Barbaras
}

Aproximaciones al problema fenomenológico y metafísico del sentimiento en Renaud Barbaras

José Manuel BeAto

\begin{abstract}
Resumo: Com Métaphysique du sentiment (2016), Renaud Barbaras propõe uma teoria do sentimento singular e radical, que, ao mesmo tempo, constitui uma nova etapa na prossecução, ampliação e aprofundamento da sua "fenomenologia da vida”. Reconhecendo a sua dívida para com Mikel Dufrenne, tal elaboração teórica afirma, porém, a sua originalidade por meio de um diálogo crítico com os fenomenólogos que problematizaram a sensibilidade e a afetividade: Martin Heidegger, Maurice Merleau-Ponty, Michel Henry e Henri Maldiney. Aquém e além do plano subjetivista dos afetos e emoções, o sentimento, para Barbaras, consiste na experiência arquiafetiva de abertura à profundidade do mundo, aquém e além dos entes finitos. Esta noção, todavia, apenas ganha seu pleno significado, claro está, quanto situada e articulada no contexto da teoria do "desejo transcendental”, entendido como avanço fenomenalizante do sujeito. O sentimento inicia o desejo ao desejado. Ele suscita e orienta o movimento insaciável do desejo em direção à profundidade inexaurível do Mundo - Mundo para o qual nos abriu de modo originário.
\end{abstract}

Palavras-chave: Sentimento; Metafísica; Desejo.

\begin{abstract}
With Métaphysique du sentiment (2016), Renaud Barbaras proposes a unique and radical theory of feeling, which, at the same time, constitutes a new stage in the pursuit, extension and deepening of his "phenomenology of life". Acknowledging his debt to Mikel Dufrenne, this theoretical elaboration nevertheless affirms its originality through a critical dialogue with the phenomenologists who have problematized the issues of sensibility and affectivity: Martin Heidegger, Maurice Merleau-Ponty, Michel Henry and Henri Maldiney. Below and beyond the subjectivist dimension of affections and emotions, feeling, for Barbaras, consists in the archi-affective experience of openness to the deepness of the world, below and beyond finite entities. This notion, however, only gains its full meaning, of course, as articulated with the theory of "transcendental desire", understood as the phenomenalizing advancement of the subject. Feeling initiates the desire to the desired. It arouses and directs the insatiable movement of desire towards the inexhaustible deepness of the World - the world to which it opened us in an originary way.
\end{abstract}

Keywords: Feeling; Metaphysics; Desire.

Resumen: Con Métaphysique du sentiment (2016), Renaud Barbaras propone una teoría del sentimiento singular y radical que, al mismo tiempo, constituye una nueva etapa en la prosecución, ampliación y profundización de su "fenomenología de la vida”. Al reconocer su deuda con Mikel Dufrenne, tal elaboración teórica afirma, sin embargo, su originalidad por medio de un diálogo crítico con los fenomenólogos que problematizaron la sensibilidad y la afectividad: Martin Heidegger, Maurice Merleau-Ponty, Michel Henry y Henri Maldiney. Aquella y más allá del plano subjetivista de los afectos y emociones, el sentimiento, para Barbaras, consiste en la experiencia arquiafetiva de apertura a la profundidad del mundo, allá y más allá de los entes finitos. Esta noción, sin embargo, sólo gana su pleno significado, claro está, como está situada y articulada en el contexto de la teoría del "deseo trascendental”, entendido como avance fenomenalizante del sujeto. El sentimiento inicia el deseo al deseado. Él suscita y orienta el movimiento insaciable del deseo hacia la profundidad inagotable del Mundo - Mundo para el cual nos abrió de modo originario.

Palabras clave: Sentimiento; Metafísica; Deseo.

\section{Introdução}

A filosofia contemporânea, de índole reflexiva, fenomenológica, existencial e hermenêutica, concedeu um lugar de elevado relevo ao sensível, à afetividade, ao sentimento, e isto para além dos escolhos clássicos de sua redução intelectualista, empirista e psicologista. Max Scheler, Martin Heidegger, Maurice Merleau-Ponty, Mikel Dufrenne, Michel Henry, Henri Maldiney, Paul Ricœur, Marc Richir e mais recentemente Renaud Barbaras, mas ainda pensadores tão diversos como Louis Lavelle,
Gabriel Madinier ou Jean Wahl, inscrevem-se nesta dinâmica. Neles encontramos uma aproximação reflexiva à problemática do "sentido íntimo", uma redescoberta da originariedade do "sensível", uma vasta fenomenologia da consciência e experiência afetivas em diálogo com a ética e a estética, uma clarificação programática do conceito de "sentimento", bem como uma hermenêutica das noções de afeção, paixão, emoção, sensação, etc.

Este movimento - amplo e heterogéneo nas suas expressões concretas - desenvolve uma reflexão que se distingue, por um lado, da problemáti- 
ca tradicional das "paixões” - amálgama nocional onde a especificidade do sentimento é subsumida, tanto quanto da psicologia e da neurobiologia das emoções. O sentimento distingue-se aqui do substrato biológico das reações afetivas, das afeções "primárias", mas também dos estados emotivos de estrita incidência psicológica ou privativa. O sentimento é, assim, afirmado no seu alcance "ultraemocional" e metafísico. Ele associa-se, por um lado, à experiência mais originária da abertura ao mundo, numa radical afetividade e, por outro, às mais altas esferas da consciência e aos níveis superiores da vivência humana, onde ganha com caráter intencional, simbólico e intersubjetivo. Ele é estado íntimo do sujeito concreto incarnado, mas também ato intencional abrindo-se à alteridade do mundo e dos outros sujeitos, ao belo, ao justo, ao verdadeiro, vencendo os limites do subjetivismo e do objetivismo. Deste modo, torna-se sentimento moral, estético, religioso, espiritual ou ontológico.

Todavia, poucos autores terão enfrentado monograficamente e programaticamente o tema de uma "metafísica do sentimento" com contornos tão originais e radicais quanto Renaud Barbaras. Tal sucede no quadro de uma reflexão que não cessa de renovar-se e aprofundar-se na afirmação do seu rigor e originalidade. O que começara, essencialmente, com uma análise fenomenológica do "a priori correlacional", quer dizer, da estrutura $a$ priori da relação intencional entre a consciência e o objeto por ela visado, elaborada a partir de Husserl, Merleau-Ponty e Patočka, desenvolve-se agora sob as formas conjuntas de uma cosmologia e de uma metafísica, ou porque não dizê-lo, de uma ontologia cosmológica.

Em Métaphysique du sentiment, Barbaras (2016) prossegue na apreensão do "sentido do ser do sujeito", a partir do mundo enquanto "processo" ou "physis", para desenvolver uma analítica do sentimento de alcance metafísico, enquanto abertura a esse mesmo mundo. A obra releva da natural audácia do pensador consequente na prossecução inspirada e meticulosa das suas intuições, pelo que ela não se compreenderá cabalmente se não for situada no contexto da evolução interna do pensamento do autor. No que respeita a este ponto, Barbaras revela uma grande generosidade para com os seus leitores neófitos. Na introdução, e em toda a primeira parte, guia-nos, límpido na profundidade, claro na densidade e destro na sinuosidade, para restituir os passos essenciais do seu percurso, onde reconhecemos algumas das propostas fundamentais já presentes em Introduction à une phénoménologie de la vie (Barbaras, 2008), La vie lacunaire (Barbaras, 2011) ou Dynamique de la manifestation (Barbaras, 2013), entre outros textos. Usando uma metáfora musical, talvez possamos dizer que o "sentimento" constituiu-se, no desenvolvimento melódico desta filosofia, como que um tema modulante que explora o primeiro harmónico da fundamental, a saber, a tónica do Desejo.

Para tal, coloca-se na senda de Mikel Dufrenne, que via no sentimento estético a via real de acesso ao mundo, e no "poético" um modo privilegiado de experienciar o sensível. Por outro lado, estabelece um conjunto de diálogos com outros fenomenólogos que pensaram a sensibilidade, o sentimento e a afetividade. Convoca criticamente Maurice Merleau-Ponty, para se posicionar aquém da perceção, Michel Henry, para criticar o enclausuramento da afetividade na "autoafeção", Martin Heidegger, para recusar a conjunção do sensível e do sentido na noção de disposição fundamental, marcada pela Stimmung da angústia e, por fim, Henri Maldiney, para infirmar a ideia de "tranpassibilidade" que anula no sentir o seu efetivo ato de acolhimento.

\section{Do sentir ao sensível}

O pano de fundo é claramente exposto. "O sensível é a modalidade própria de aparecer do ser" (Barbaras, 2016, p. 14) e, "portanto, o ser do próprio ser" (p. 41), mas além de qualquer empirismo, fenomenismo, ou naturalismo sensacionista. Na verdade, o sensível "preserva a transcendência e profundidade do ser nessa manifestação". O sensível, como manifestação de ser, reveste-se de uma ambiguidade fundamental que toma a forma de uma obscuridade na clareza, de uma ausência na presença, de uma profundidade na superficialidade (Barbaras, 2016a, p. 13).

Toda a sensibilidade reveste-se assim de um alcance e dimensão ontológico-metafísica. A dinâmica do sentir realiza uma abertura fundamental ao aparecer do ser, não sob a forma de vivências ou estados subjetivos, e sequer já como visada constituinte e totalizada, mas como "acolhimento do aparecer sensível" do mundo na sua manifestação. Mas a novidade de Barbaras consiste na inversão da perspetiva "clássica". O sensível não é "objeto de uma sensibilidade", mas é a modalidade própria do advir do mundo como mundo. Passa-se assim "da constituição do sensível (desde logo entendido como sentido) pelo sujeito senciente à ostensão do mundo no e através do sensível” (Barbaras, 2016a, p. 41). Como o indica claramente Barbaras: "o caminho da fenomenalidade não vai do sentir para o sentido e deste para o mundo (versão clássica); mas ele vai do mundo para o sensível e deste para o sentido" (Barbaras, 2016a, p. 42). Assim, a investigação que conduz ao sentimento começa por um "procedimento regressivo" que neutraliza toda a referência ao sujeito, evitando, deste modo, qualquer tendência subjetivista.

Neste contexto, a fenomenologia da afetividade de Renaud Barbaras remeterá para uma ontologia entendida como cosmologia: o ser é, em última análise, o mundo, melhor, o "processo do mundo" entendido como "arquimovimento". "A essência da essência não é outra que o mundo como fonte e princípio de toda a existência”, escreve o fenomenólogo (Barbaras, 2016a, p. 104). Parece-nos que, por esta via, Barbaras vivifica a querela em torno da questão da Fenomenologia poder constituir-se ou não como "filosofia primeira", revogando, ou não, por essa via, toda e qualquer metafísica que dela não proceda, ou a ela não se reconduza.

A “dinâmica fenomenológica” suscita ou pro- 
pulsa, com efeito, uma metafísica, mas uma metafísica não substancialista. Uma "metafísica negativa", afirma Barabras, porquanto se trata de uma metafísica do devir e do acontecimento como "devir do devir" ou do "puro advir”, tão indeterminável quanto irrepressível e único. Este puro acontecer é o "único modo de não ser verdadeiramente coisa alguma sem ser nada"1. (Barbaras, 2016a, p. 102). Trata-se de um "não-ser efetivo e ativo" que vem infletir ou alterar um devir. Estamos perante uma "metafísica da facticidade" que, aquém ou além das “causas primeiras”, medita o caráter originário dos "factos últimos" na sua pura efetividade e fora de uma causalidade genética. O primeiro dos quais é o "facto do Ego". Estes factos primeiros "têm lugar" não relevando de nenhuma essência que os contenha como possibilidade ou que traduza um pressuposto explicativo da sua ocorrência. O primeiro evento, e o mais fundamental, é o "arquievento" que afeta o "arquimovimento" e do qual sucede a separação originária do "sujeito" (Barbaras, 2016a, p. 102).

Tal investigação pretende ser, contudo, rigorosamente fenomenológica, permanecendo na estrita observância da metodologia husserliana e do seu propósito fundamental, escapado aos critérios críticos de Dominique Janicaud, quanto à pulverização ou à expansão ilícita da Fenomenologia.

\section{Vida e desejo}

Tudo isto se passa no âmbito do questionamento fundamental de Renaud Barbaras que, inserido numa retomada e renovação, original e fecunda, do projeto fenomenológico, consiste em indagar "o sentido de ser do sujeito da correlação". (Barbaras, 2011, p. 142; Barbaras, 2015, p. 352). Ao mesmo tempo que pertence ao mundo, o sujeito está dele separado sendo a sua condição de fenomenalização. O sujeito caracteriza-se como "viver", e a fenomenologia da correlação torna-se uma "fenomenologia da vida". A vida deve ser tomada no seu "sentido originário": aquém da distinção entre o "estar vivo" (leben) e o "vivenciar" alguma coisa (erleben $)^{2}$, e além da antinomia da transitividade do agir e da intransitividade da existência (Barbaras, 2011, 2015, 2016).

É nesta charneira do "viver" que brota o "desejo”. Este é, em última análise, a sua essência, na exata medida em que o "sentido de ser do sujeito é Desejo” (Barbaras, 2015, p. 353). O desejo constitui a intencionalidade fundamental, o movimento para o "outro", enquanto esse "outro" viria suprir uma "falta”. Esta "falta" não é uma necessidade empírica, mas uma lacuna constitutiva, uma desproporção interna intransponível, uma distância de si a si-mesmo do próprio sujeito. O desejo corresponde a uma dinâmica de reconciliação e realização. No desejo, o sujeito experiencia o próprio excesso de vitalidade do mundo, e a sua própria "lacuna ontológica” face ao mundo (Barbaras, 2011, p.148).

"Qual o modo de ser do sujeito do sentir?", pergunta Barbaras. Ele é pensado sob o signo do

\footnotetext{
1 «la seule manière de de n'être vraiment rien sans être néant »
}

2 O autor usa os termos alemães movimento "cuja presença a si é ausência de si”, e não da substância ou da identidade estável (Barbaras, 2016a, p. 15). Neste movimento, ele avança e penetra na profundidade do mundo para o fazer aparecer, revelando ainda o excesso interno do sensível: tal releva da "dualidade do pertencimento e da diferença ontológica” (Barbaras, 2016a, p. 19) ${ }^{3}$. O desejo é esse "movimento subjetivo originário, esse movimento vivo", que não corresponde a uma "necessidade" ou "falta empírica". Não é falta de algo determinado que um qualquer objeto ou ente poderia satisfazer. Nesse sentido, é insaciável, porquanto ele é desejo de nada, ou seja, de nenhum ente em particular. Em última análise, é "desejo de ser”, ou seja, "desejo de mundo”. Não se trata, pois, do desejo em sentido psicológico, mas bem de um “desejo transcendental” (Barbaras, 2016a, p. 21-23).

$\mathrm{O}$ ser do sujeito informa-nos sobre o ser do mundo. O ser do mundo é movimento, processo ontogenético de delimitação e diferenciação interna, de produção de entes a partir de si-mesmo como "fundo originário indiferenciado" e originante. Renaud Barbaras chama a este "processo do mundo", o "arquimovimento". Este "arquimovimento", pelas suas delimitações e diferenciação internas, pela produção de entes, constitui um primeiro nível de fenomenalização e de finitude. Esta manifestação primeira, anónima, não é ainda, em si-mesma, aparecer para ninguém (Barbaras, 2016a, p. 21-26).

O processo do mundo consiste no "devir-mundo do mundo correspondente ao surgimento de uma multiplicidade de entes por diferenciação do fundo". O Mundo surge como unidade de multiplicidade, como totalidade unitária cuja identidade e indivisibilidade nunca são completamente negadas por essa diferenciação. Ele é "potência de produzir diferenças" mas, mais anda, "sobrepotência” que excede tudo quanto produz, pois, jamais se esgota no produzido ou na obra realizada (Barbaras, 2016a, p. 28-29). Aqui se funda o excesso do sensível, na profundidade e profusão do seu aparecer.

O sujeito, enquanto movimento, não revela apenas a sua pertença, a sua inscrição no mundo, mas ainda uma autêntica "comunidade" ou "parentesco ontológico" com ele, além de uma mera relação de inclusão (Barbaras, 2016a, p. 24-25). A particularidade do sujeito face aos demais entes é que o seu movimento realiza um segundo plano de fenomenalização. O aparecer torna-se "aparecer a...”. Este aparecer secundário é uma fenomenalização subjetiva, uma doação de sentido, que envolve uma perda do mundo em benefício da manifestação dos entes finitos. O sujeito possibilita, sem contudo ser o seu artesão, uma manifestação "secundária”, um segundo momento do aparecer do qual é o destinatário: "faz aparecer os entes do mundo". Porém, tal sucede porque a sua separação do mundo é correlativa da sua pertença ao mundo. Mas essa "individuação" resulta de uma finitização e de uma limitação da potência do mundo; ela consuma uma "perda do mundo". O regime da nossa individuação é “separação” e não já simples “diferenciação”, ele é

\footnotetext{
3 Por sugestão do próprio Renaud Barbaras, opta-se aqui por traduzir "appartenance" por "pertencimento". Noutros locais, poder-se-á encontrar o termo "pertença".
} 
limitação de potência, cerceamento da "arquivida". Para Barbaras, esta cisão no seio do "arquimovimento" não pode ser obra do próprio "arquimovimento"; a limitação da sobrepotência não procede de si-mesma, sendo algo que lhe acontece. Resulta de um "arquievento" que afeta o arquimovimento. Este acontecimento é um puro surgimento acausal que desmente o princípio de razão suficiente, pois não está inscrito como possibilidade na potência do mundo: é um "clinamen metafísico" (Barbaras, 2016a, p. 77-79).

A condição do sujeito resulta, assim, do traumatismo desse acontecer sem causa nem razão, que, em si, não é nada e apenas se observa nos seus efeitos: um exílio ontológico face à sua própria origem e ser. Esse exílio é o fundamento do Desejo que, distinto da falta e da tendência é o que, visando entes finitos, deseja, todavia, superar a cisão diferenciadora. Designa e desenha-se nele a aspiração a reencontrar o ser, o mundo.

Este duplo aparecer - primário e secundário - manifesta e resulta, portanto, de uma "dupla finitude": ontológica e fenomenológica. O ser manifesta-se individualizando-se nos entes. Nesse mesmo processo, ele retrai-se e retira-se configurando-se a "finitude ontológica". A "finitude fenomenológica" consiste no aparecimento dos entes ao sujeito - por via da determinação e da constituição do "sentido" sobre o sensível - que se dá com uma perda do próprio mundo (Barbaras, 2016a, p. 54-55). É assim claro que o "sentido" procede de uma "privação no seio do ser", mas que permite o surgimento do sujeito (Barbaras, 2016a, p. 112). O sentido do ser envolve o seu aparecer a um sujeito: estamos além do realismo e do subjetivismo.

O surgimento do sentido corresponde ao aparecimento do ente enquanto tal, ao abandono do seu lastro ontológico, pois a sua manifestação a um sujeito implica a concomitante "perda" do mundo. A apreensão subjetiva do ente implica o ausentamento (absentement) do mundo (Barbaras, 2016a, p. 111). O movimento do sujeito torna-se intencional e o desejo torna-se visada de um objeto concreto. Nesta dinâmica fenomenológica, a particularidade da visada reside, contudo, no facto de constituir um mistura de atividade e passividade, resultante da conjunção da dupla manifestação, já enunciada. Assim, o movimento do sujeito desejante encontra o movimento diferenciador do mundo (Barbaras, 2016a, p. 113).

\section{O Sentimento}

Avançado o Desejo - como "modo de ser" do sujeito - somos conduzidos a uma "fenomenologia da afetividade", na qual este aparece como o "Afeto fundamental “, comoção que projeta extaticamente para o mundo (Barbaras, 2011, p. 125-146). Esta fenomenologia da afetividade é, todavia, prosseguida e relançada em termos diversos, através da introdução, a partir de Métaphysique du sentiment, precisamente, da noção do "sentimento", até então ausente. Em Le Désir et le Monde, este desenvolvimento analítico será plenamente validado. O sentimento é aí reafirmado como a "experiência arquiafetiva" que possibilita - precedendo e comandando - o "desejo". Com ele se inicia originariamente o desejo ao desejado. (Barbaras, 2016b, p. 167-183) ${ }^{4}$.

Nem a fenomenologia do sentir nem a metafísica do sentimento se centram na intencionalidade constituinte do sentido por parte do sujeito senciente. É sempre a ostensão do mundo que está em jogo no e pelo sensível: do mundo para o sensível e do sensível para o sentir e, apenas então, para o sujeito senciente, destinatário de um aparecer secundário, condição de uma segunda fenomenalização (Barbaras, 2016a, p. 42) Realiza-se uma époché da existência subjetiva. Tudo deve partir do aparecer do mundo, e da "abertura ontológica do mundo pelo sensível” sem cedência alguma ao subjetivismo.

Como define Renaud Barbaras o sentimento, no interior da sua própria problemática? Cito: "Chamamos sentimento a essa dimensão ao mesmo tempo existencial (existentiale) e contraevential (contre-événementiale) na qual se atesta a sutura originária do que foi separado pelo arquiacontecimento" (Barbaras, 2016a, p. 172). Ele é o que permite superar a cesura fundamental e atestar do pertencimento originária ao mundo, na sua sobrepotência e arquivida. Noutros termos, o sentimento é a abertura originária à profundidade do mundo como o que transcende todo o ente finito.

Mas se o sentimento é bem abertura ao mundo na sua plenitude e profundidade, ele é ainda um “operador de ipseidade”, quer dizer, “que é no sentimento que o si faz a experiência (épreuve) privilegiada dele-mesmo". Na verdade, é no sentimento que o sujeito faz a experiência mais imediata, íntima e evidente de si-mesmo e, neste sentido, ele é sempre e em primeiro lugar "sentimento de si" (Barbaras, 2016a, p. 179).

Ficam claros a dimensão e o alcance ontológico do sentimento. Neste duplo movimento de abertura ao mundo e de ipseização ele é um "existencial ontológico", ou o "existencial da ontologia" (Barbaras, 2016a, p. 179). Tudo isto está bem distante da problemática tradicional das paixões, está bem além da psicologia ou da neurobiologia das emoções, assim como se situa longe de qualquer subjetivismo ou psicologismo emotivista. O sentimento distingue-se das emoções e dos afetos em geral. Não se confunde com determinadas tonalidades emotivas ou vividos de consciência afetiva que sejam reações a determinados objetos ou situações. Longe de se socorrer da Psicologia, poderia ao invés, socorrer e fundar uma "teoria geral do sentimento" com seus desenvolvimentos de índole psicológica (Barbaras, 2016a, p. 179).

Nesta tematização, Barbaras é tributário de Mikel Dufrenne, que, em Phénoménologie de l'expérience esthétique (1953), desenvolve uma filosofia do sentimento cujos contornos são retomados e os pressupostos revalidados em Le Poétique (1973) e L'inventaire des a-priori: recherche de l'originaire (1981). O "sentimento" é analisado como via de acesso ao sentido na "experiência estética”. Esta úl-

4 Os elementos essenciais da metafísica do sentimento são retomados no capítulo VI de Le désir et le monde (Paris: Hermann, 2016). 
tima, sendo elevada a modelo privilegiado da experiência do mundo, permitirá investir o sentimento de um alcance e função ontológicos: “o acesso ao próprio ser sensível para além dos objetos sensíveis”, sintetiza Barbaras (Barbaras, 2016a, p. 182). Para Dufrenne, a perceção estética culmina e consuma-se no sentimento, que a prolonga e aprofunda (Dufrenne, 1992, p. 471-472). O sentimento é um modo da intencionalidade no qual, afirma, "a consciência se reúne de algum modo e se aprofunda para estar totalmente recetiva ao sensível e para experienciar no percecionado a plenitude e a profundidade de um mundo" (Dufrenne, 1973, p. 83). Nele se realiza, numa dinâmica de acolhimento e participação, um "acabamento da perceção" para além da pura presença sensorial e da distância representacional, bem como um certo modo de conhecimento, não conceptual nem representativo.

A “profundidade do objeto estético" é o correlato da "profundidade humana" alcançada no sentimento, mas ambas estas esferas de profundidade estão unidas na profundidade do próprio mundo (Dufrenne, 1992, p. 494). A experiência estética tem, de facto, uma "significação ontológica": revela a consubstancialidade do homem e do mundo, e coloca-se na dinâmica naturante do real - o plano do originário, que é "impensável” mas passível de "expressão" e cujo "sentido afetivo" é apreendido pelo "sentimento". Trata-se de uma dimensão de sentido que não é fundada ou constituída pelo homem, mas de que este é veículo de manifestação: “o real não recebe do homem o seu sentido [...] o ser suscita o homem para ser a testemunha e não o iniciador desse sentido” (Dufrenne, 1992, p. 665-666).

Assim se entende porque Dufrenne, na sua "investigação sobre o originário", retomará a noção de sentimento, colocando-a sob no prisma de uma "filosofia da natureza", pensada como "Fundo" ou "substância" fecunda, geradora de ser e sentido. Mais de vinte depois da tese, dirá então Dufrenne,:

Chamamos sentimento a esse movimento pelo qual a consciência descobre de novo a unidade originária da qual emerge, pressentindo por aí a Natureza: todo o sentimento é de algum modo sentimento da Natureza [...] o sentimento é o modo de abertura ao mundo pelo qual se envolve, até se esquecer de si, a pessoa inteira, um sujeito que não está já somente atento para apreender o objeto mas que o recolhe e interioriza (Dufrenne, 1981, p. 295-296).

Deste modo, tal elaboração conceptual do sentimento - de função noética e alcance ontológico - em tudo se distingue, já o dissemos, da emoção - de incidência psicológica. A emoção apenas "abre a eventos e entes intramundanos", enquanto o sentimento "abre um mundo" (Barbaras, 2016a, p. 183). A emoção é reação, comentário, resposta a um ente singular mediante um afeto determinado. O sentimento é abertura originária sem especificação afetiva.

O sentimento é, desde logo, mais profundo e originário do que a perceção cuja visada intencio- nal constitui entres finitos e destacados do mundo. Enquanto "experiência (épreuve) arquiafetiva”, ele está ao mesmo tempo aquém e além da perceção, pois, não nos dá nenhum objeto e abre a uma transcendência que excede a do objeto (Barbaras, 2016b, p. 171). Afastamo-nos aqui de Maurice Merleau-Ponty, que não terá reconhecido o valor específico da afetividade. Acresce Barbaras que com a sua “teoria da carne", o autor de Le visible et l'invisible acentuou a proximidade e intimidade fundamentais entre o sujeito e o mundo. Ora, para Barbaras, o sentimento ganha o seu significado dentro da "alienação fundamental" e do "exílio radical" do sujeito, sendo, justamente, o modo de iniciação deste último àquilo de que foi separado pelo "arquiacontecimento": a sobre potência e profundidade do mundo. O sentimento atesta em nós da nossa comunidade com o mundo, mas dentro da condição exilada decorrente da "cissão acontecimental” (Barbaras, 2016a, p. 207-213).

A “ipseização" realizada pelo sentimento não significa, todavia, uma clausura, um fechamento sobre si, uma "autoafeção", pois, "intimidade e ipseidade apenas se realizam como abertura à profundidade do mundo" (Barbaras, 2016a, p. 180). Somente acedemos à nossa própria profundidade indo ao encontro da profundidade do mundo: intimidade e transcendência convergem. Entrar em si e sair de si coincidem. A intimidade e a profundidade são uma experiência de despojamento e disponibilidade que Renaud Barbaras designa de "extimidade” (extimité) existencial (Barbaras, 2016, p. 193). O regime de fenomenalização do sentimento situa-se aquém e além da distinção do interior e do exterior. Na abertura originária por ele configurado reúnem-se a "ostensão do mundo" e a "vinda (avènement) de um si" (Barbaras, 2016, p. 201). Estamos, deste modo, nos antípodas da fenomenologia da afetividade de Michel Henry, centrada na "afeção de si por si” e empenhada em cindir totalmente a afetividade e o sentir, no contexto da insistente recusa do que designa por "monismo ontológico"5. Ora, para Barbaras, ao invés, é bem no sentimento que o termo "sentir" atinge "a plenitude do seu sentido", na medida em que ele é "indistintamente e necessariamente sentir do mundo para além da perceção e sentir-se a si-mesmo para além da afeção”, e que tal sucede de um modo desafetado de todo o conteúdo objectual ou tonalidade afetiva específica. Tal se realiza, contudo, numa intencionalidade mais fundamental que nos dá esse "nada de ente que é o mundo” (Barbaras, 2016a, p. 202).

\section{Um "vazio de emoções"}

Se o sentimento é abertura e acesso à profundidade do mundo, ele está simultaneamente aquém e além dos objetos concretos e dos vividos afetivos

\footnotetext{
$5 \quad$ A sensibilidade é definida por Michel Henry como o "poder de sentir alguma coisa, isto é de o receber e de ser afetado por ele, tanto quanto essa afeção se realiza por intermédio de um sentido e, finalmente, do sentido interno". A afetividade, pelo contrário, "é a forma da essência na qual esta é afetada não por outra coisa mas por si mesma, de tal modo que esta afeção original como autoafeção, como sentimento de si, a constitui e a define" (Henry, 1990, p. 578).
} 
finitos a eles associados. A abertura por ele realizada é, de um modo mais fundamental, a "condição originária” do conhecimento sob forma de objetos, bem como das emoções que podem suscitar esses objetos (Barbaras, 2016a, p. 186). O sentimento não tem assim nenhum conteúdo emocional ou tonalidade afetiva determinados, que, comentando ou reagindo a qualquer ente finito ou vivência, se interponha entre o sujeito e si-mesmo, quer dizer, entre o "si" o e o "mundo". Realiza-se, pois, um certo "vazio de emoções" que é condição da máxima abertura e acesso à transcendência do mundo. Nada sinto para além de um abalo fundamental, na ambivalência de um afundamento e de uma exaltação. A carência e o movimento insaciável do desejo brotam daqui. Desde já percebemos que o sentimento é constitutivo do desejo, que há entre ambos uma copertença. É o sentimento que orienta o desejo na direção do mundo, para além dos entes finitos (Barbaras, 2016a, p. 186-187 e 236-237). Por outro lado, neste vazio emotivo, o "si" reencontra-se, toca a sua própria vida na tangência da "arquivida", na espessura e plenitude do mundo.

O sentimento traduz uma "intencionalidade originária": ele é "a vivência da transcendência do mundo na sua inacessibilidade fundamental" (Barbaras, 2016a, p. 186-187). O mundo de aquém da cisão originária, do "arquievento", é dado como perdido, mas, ainda assim, é de algum modo dado, como "nostalgia ontológica", ou seja, na "provação de uma plenitude à distância", e numa promessa de reconciliação, de saída do "exílio ontológico" (Barbaras, 2016a, p. 256). Defrontamos assim o aparente paradoxo de um vazio de emoções que é "sentimento de nada" mas, ao mesmo tempo, uma "tonalidade fundamental" reveladora da presença-ausente do mundo (Barbaras, 2016a, p. 188-189).

O sentimento metafísico é, assim, nostalgia, mas também incitação, pois proporciona ao desejo o "saber originário daquilo que ele procura" (Barbaras, 2016a, p. 257), dá a entrever o mundo como solo onde vai exerce-se o seu poder de fenomenalização. Sentimento e desejo estão de lados opostos do "arquiacontecimento".

\section{Nem "angústia" nem "tranpassibilidade"}

O que Barbaras chega a designar como "tonalidade fundamental" ou "sentimento de sentimento" (Barbaras, 2016a, p. 189) não se confunde porém com a "disposição fundamental", pensada por Martin Heidegger. O "sentimento" não designa um afeto particular dotado, face a outros, de um estatuto privilegiado ou "insigne", na expressão de Heidegger. Sabemos como a "angústia" constitui ou revela ao Dasein o seu modo de ser primeiro como "ser-no-mundo enquanto tal" (Heidegger, 2005, p. 155) ou ainda o facto do mundo e do existente como tal existirem face ao nada (Barbaras, 2016a, p.229). A Befindlichkeit heideggeriana é, na caracterização que dela faz Barabras, "indistintamente uma abertura a si mais radical que a simples experiência de um conteúdo afetivo e uma abertura ao mundo mais originária que o simples conhecimento de entes in- tramundanos" (Barbaras, 2016a, p. 217). Daqui resulta a sua proximidade com a noção de sentimento visada por Barbaras. Porém, esta "afeção", enquanto "disposição" é já um "compreender", pois constitui a "unidade originária ou o co-pertencimento do sentido e do sensível" (Barbaras, 2016a, p. 219). O sensível é, portanto, apreendido no horizonte do sentido. Os dois existenciais do "compreender" e da "afeção" estão, nesta medida, reunidos. Esta teoria da afetividade, afinal, não corresponde ao conceito de sentimento do nosso autor nem se situa no mesmo plano. Trata-se ainda, em Heidegger, do plano da "finitude secundária" e da "ostensão dos entes mundanos nas qualidades sensíveis", ainda que de um modo não-objetivo (Barbaras, 2016a, p. 220). Por outro lado, ao estar situada no âmbito da "analítica do Dasein", esta conceção da afetividade resulta ainda, segundo Barbaras, num subjetivismo, mesmo que "aprofundado e deslocado". O ser está no mundo, mas não se trata de compreender o sujeito como constituído pelo mundo no processo do seu "ausentamento".

Enquanto disponibilidade constitutiva, o sentimento é abertura à profundidade indeterminada que é o mundo. Enquanto abertura, o sentimento, não apenas não pode ser reconduzido à "angústia", como lhe é oposta. Ele não tem um caráter "opressivo e repulsivo" que contrai e fecha o sujeito sobre si. Ao invés, envolve uma "dilatação existencial" e uma efusiva disponibilidade à participação. Se na angústia assistimos ao "nascimento do nada", no sentimento acedemos a uma plenitude que superabunda além dos entes finitos, esconjurando esse mesmo nada (Barbaras, 2016a, p. 232-235). A negação ou nadificação dos "entes" toma um sentido oposto. O sentimento envolve uma vivência de despojamento que é abalo e vulnerabilidade, mas, ao mesmo tempo, exaltação e alegria, bem distintas da angústia.

Como temos vindo a observar, na "metafísica do sentimento" proposta por Barbaras, algumas dualidades tradicionais são dialectizadas ou superadas na fluência oscilatória da sua correlação: atividade / passividade; interioridade / exterioridade; matéria / forma. Há uma atividade da passividade, que reside na capacidade de abertura e acolhimento do outro e do mundo, que chega a designar por "disponibilidade"6. Há uma convergência da intimidade e da transcendência na "profundidade" que chega a designar por "participação". Por outro lado, o sentimento, abrindo à profundidade do mundo, situa-nos, de algum modo, aquém da disjunção de matéria e forma do "aparecer secundário".

Por esta via, Barbaras afasta-se ainda de Henri Maldiney, que, para constituir uma autêntica teoria do sentir distinta da perceção, se centrou na noção de "tranpassibilidade". O "sentir" é visto como pura recetividade passiva, destituída de visada intencional, e de qualquer dinâmica de projeto (Barbaras, 2016a, p. 238-239), como pura abertura originária

6 Não resistimos a fazer notar que este é um termo particularmente marceliano e que a sua utilização por Mikel Dufrenne em Phénoménologie de l'Expérience Esthétique é próxima de referências explicitas a Gabriel Marcel (Dufrenne, 1992, p. 469) 
ao indeterminado. É “transpassível” o que não é passível de nada, ou seja, o que está além ou aquém de toda a antecipação ou prefiguração, numa abertura ao "nada" enquanto nada de ente e nada de possível (Barbaras, 2016a, p. 241). Ora, a tal descrição corresponde o "sentir do acontecimento": a vinda do evento como aquilo que é sem razão nem causa (Barbaras, 2016a, p. 243-244). A sobrevinda do evento faz aparecer o mundo como o nada de onde provem. Esta afetividade está aquém e além de qualquer doação de sentido e de todo o subjetivismo, e nisto coincide com a proposta de Barbaras. Por outro lado, ela é de sobremaneira interessante porque a sua recusa da intencionalidade - como visada de objeto - não resulta num fechamento do sentimento na pura imanência de uma autoafeção, como em Henry. Maldiney e Barbaras partilham, deste modo, algumas coordenadas do problema. Na verdade, em ambos há uma teoria da "afetividade originária" como "iniciação à profundidade de um mundo além do campo dos fenómenos" (Barbaras, 2016a, p. 247) Mas a sobrevinda do evento, em Maldiney, não é apenas um abalo na trama do mundo mas também uma rutura com este. Ora, a superação da rutura acontecimental - a falha do arquiacontecimento - rumo ao mundo é o que está em jogo no sentimento, em Barabaras. Mas mais ainda, já o sabemos, o que está ainda em causa no nosso autor, é que o sentimento é ainda uma "dimensão do sujeito" pois envolve uma "experiência" e um transitividade como "sentimento de e por". Algo que, precisamente, a noção de "transpassibiliade" anula (Barbaras, 2016a, p. 250). Há, além da visada de objeto e da projeção do possível, uma intencionalidade fundamental ou superior que é condição da abertura à profundidade do mundo, enquanto é negação dos entes, mas é, também, ontologicamente plena e consistente. A abertura deve efetivamente abrir àquilo que abre! Ela abre menos ao "nada de entes" do que é abertura à "totalidade viva do mundo" além dos entes; ela abre menos ao impossível ou transpassível do que é abertura à totalidade do possível. Acresce ainda que levando ao extremo a ideia de passividade, Maldiney anula a possibilidade da recetividade. Por isso, Barbaras avança a ideia de uma "atividade sem ato", quer dizer, "sem objeto nem projeto", em que consiste o "acolhimento", e que realiza a "abertura" (Barbaras, 2016a, p. 254). Disponibilidade, acolhimento, participação são termos que expressam essa "atividade na passividade”, experienciada no sentimento, para infirmar a ideia de "tranpassibilidade" que anula no sentir o seu efetivo [ato de] acolhimento.

\section{Sentimento e Desejo}

Como já o dissemos, existe uma copertença do desejo e do sentimento. Estes são apresentados como duas dimensões do sujeito, constitutivas e codependentes, mas correspondentes a duas regiões ontológicas diversas. Sentimento e desejo estão de lados opostos do "arquievento". Afirma-se que o sentimento - enquanto abertura ao mundo - comanda, orienta e incita o desejo - enquanto visada e avanço perpetuamente insatisfeito. O desejo é o movimento em direção àquilo para que abre o sentimento, e assenta na "iniciação originária" proporcionada por este. O sentimento é inseparável e constitutivo do desejo, sendo que cabe a este último realizar e prolongar o sentimento. Neste ponto, Barbaras parece fazer uma cedência a um dos dualismos que todavia quer superar, ao dizer que "o sentimento está para o desejo como a matéria para a forma" (Barbaras, 2016a, p. 256-257; 260). O desejo exerce a sua dinâmica sobre o solo, ou o fundo do sentimento que revela o mundo no seu ausentamento.

A cabal articulação do desejo e do sentimento envolveria dar conta, de modo mais atento e moroso, de Le désir et le monde, onde a problemática do desejo é retomada, sintetizada e relançada, e onde o sentimento é reposicionado na mais ampla teoria do "desejo transcendental”. Algo é claro e central: no desejo, a relação ao mundo é dupla. Por um lado, ele torna possível a fenomenalização dos entes do mundo, enquanto a priori de todo o aparecer. Por outro lado, ele dá conta de uma "iniciação originária” e de uma incitação fundamental à profundidade e sobrepotência do mundo, aquém e além dos entes finitos (Barbaras, 2016b, p. 173). Nisto, o desejo depende do sentimento (como experiência arquiafetiva do originário e despojamento radical que o acolhe), ao mesmo tempo que ele realiza a vocação própria desse mesmo sentimento, precisamente, a de nos abrir ao mundo e à "arquivida”.

A experiência estética e a experiência amorosa são duas dimensões em que o sentimento aparece na sua essência e plenitude. Já aludimos à primeira por ocasião da referência a Dufrenne, resta, para concluirmos o nosso percurso, abordarmos sucintamente a segunda. Algo é certo, o amor não está do lado das emoções e afetos mas do lado do sentimento metafísico. O “erótico é ontológico” e, nessa exata medida, "o ontológico pode ser apreendido no erótico” (Barbaras, 2016a, p. 262). Como é descrito o amor? Como "aquilo que, numa passividade superior, abre a um outro na sua alteridade e inapreensibilidade mesmas" (Barbaras, 2016a, p. 264). No sentimento amoroso, o "outro" constitui-se como um mundo, melhor, como uma "cristalização" do mundo, ou uma via de acesso ao próprio mundo na sua inesgotável fecundidade. Deste modo, fazemos a experiência (épreuve) de uma alteridade e inexauribilidade que suscita o desejo: desejo do mundo do outro, ou do outro enquanto mundo. $\mathrm{Na}$ experiência amorosa, sentimento e desejo constituem um abalo radical e uma intensificação existencial face ao mundo e à vida que nele se revela. Vida e mundo, estes, que queremos penetrar ou com a qual nos queremos fusionar, mas que se mantêm sempre inatingíveis. No sentimento amoroso, um radical despojamento é condição da mais plena disponibilidade, que realiza a máxima abertura ao outro e a máxima proximidade a si-mesmo, numa convergência de intimidade e de transcendência (Barbaras, 2016b, p. 224-228).

Face ao brevemente exposto, torna-se evidente que o "amor" é bem o paradigma de todo o sentimento, o "sentimento por excelência", ou o "senti- 
mento dos sentimentos”. No fundo, não é já somente "sentimento disto ou daquilo", mas o "próprio sentimento", o sentimento na sua essência (Barbaras, 2016b, p. 222). Por esta via, o "sentimento ontológico", ainda que revelando a univocidade do ser do mundo e do ser do homem num contínuo cosmológico, talvez permita o afloramento personalista desta radical e singular "fenomenologia da afetividade”. E talvez uma reconfiguração da epistemologia das paixões, emoções e sentimentos - ampla e integradora - possa ser fundada. Tal seria a sugestão que faríamos ao autor de Métaphysique $d u$ sentiment.

\section{Referências}

Barbaras, R. (2013). Dynamique de la manifestation. Paris: Vrin.

Barbaras, R. (2015). Introduction à une phénoménologie de la vie. 2. ed. Paris: Vrin.

Barbaras, R. (2011). La vie lacunaire. Paris: Vrin.

Barbaras, R. (2016). Le désir et le monde. Paris: Hermann.

Barbaras, R. (2016). Métaphysique du sentiment. Paris: Cerf.

Dufrenne, M. (1981). Esthétique et philosophie: Tome 3. Paris: Klincksieck.

Dufrenne, M. (1981). L’inventaire des a-priori: recherche de 1 'originaire. Paris: Christian Bourgeois.

Dufrenne, M. (1992). Phénoménologie de l'expérience esthétique: Tome I, L'Objet esthétique. Paris: PUF.

Dufrenne, M. (1992). Phénoménologie de l'expérience esthétique: Tome II, La perception esthétique. Paris: PUF.

Heidegger, M. (2005). Etre et temps. Trad. E. Martineau. Paris: Authentica.

Henry, M. (1990). L'essence de la manifestation. 2. ed. Paris, PUF.

José Manuel Beato é doutorando em Filosofia pela Universidade de Coimbra, com Tese sobre A metafísica e moral de Vladimir Jankélévitch, e Mestre em Filosofia pela Universidade de Coimbra, com a Dissertação $O$ sentimento ontológico em Gabriel Marcel, sob a orientação da Profa. Dra. Maria Luísa Portocarrero F. Silva. Licenciado em Filosofia pela Faculdade de Letras da Universidade de Coimbra - FLUC (Portugal), é membro da Association International 'Présence de Gabriel Marcel' (Paris, França); colaborador da Unidade de Investigação \& Desenvolvimento "Instituto de Estudos Filosóficos"; colaborador do Centro de Estudos Clássicos e Humanísticos da FLUC. Foi bolseiro da Fundação para a Ciência e Tecnologia entre 2014 e 2018 (SFRH/BD/92466/2013). É ainda pós-graduado em Ciências Documentais pela FLUC da Universidade de Coimbra, assim como concluiu o Curso Complementar de Canto do Conservatório de Música da mesma cidade. Email: jose.beato71@ gmail.com 